\title{
Towards a compositional analysis of German light verb constructions (LVCs) combining Lexicalized Tree Adjoining Grammar (LTAG) with frame semantics
}

\author{
Jens Fleischhauer Thomas Gamerschlag Laura Kallmeyer Simon Petitjean \\ Heinrich Heine University Düsseldorf, Germany \\ \{fleischhauer, gamer,kallmeyer, petitjean\}@phil.hhu.de
}

\begin{abstract}
Complex predicates formed of a semantically 'light' verbal head and a noun which contributes the major part of the meaning are frequently referred to as 'light verb constructions' (LVCs). In the paper, we present a case study of LVCs with the German posture verb stehen 'stand'. In our account, we model the syntactic as well as semantic composition of such LVCs by combining Lexicalized Tree Adjoining Grammar (LTAG) with frames. Starting from the analysis of the literal uses of posture verbs, we show how the meaning components of the literal uses are systematically exploited in the interpretation of stehen-LVCs. The paper constitutes an important step towards a compositional and computational analysis of LVCs. We show that LTAG allows us to separate constructional from lexical meaning components and that frames enable elegant generalizations over event types and related constraints.
\end{abstract}

\section{Light verb constructions}

Light verb constructions (LVCs) are complex predicates consisting of - at least - two lexical elements forming a joint predication. The grammatical head of the construction is a semantically light verb which does not express the same predicational content as it does in its non-light ('heavy') uses. Rather, the predicational content is mainly contributed by a nominal element which is either realized within an NP or as a PP as illustrated by the German examples in (1-a) and (1-b), respectively.
a. ein Bad nehmen
'to take a bath'
b. unter Beobachtung stehen
'to be under surveillance'

In its light use as in (1-a) the verb nehmen 'take' does not express a change of possession as it does in its heavy use: ein Bad nehmen 'take a bath' does not denote an event in which an individual is taking possession of a bath. Instead, the LVC in (1-a) denotes an event of bathing with the meaning mainly contributed by the noun Bad 'bath'. Likewise unter Beobachtung stehen in (1-b) does not refer to a situation in which someone exhibits the particular posture specified by stehen 'stand' in its heavy use but rather means that someone is the undergoer of the activity expressed by the eventive noun Beobachtung 'surveillance'. As illustrated by the examples, the nominal element used in an LVC is characteristically an eventive noun which determines the event denoted by the LVC as a whole. In this regard, Butt and Geuder (2001) state that light verbs make a (often just subtle) semantic contribution to the predication and are not able to denote full-fledged events of their own (in contrast to their heavy pendants).

Various authors (e.g. Fleischer 1997; Fellbaum et al.|2006) consider LVCs as idioms since constructions of this type often have a conventionalized interpretation and especially the light verb cannot be interpreted literally. In their discussion of idioms, Nunberg et al. (1994) argue that idiomaticity does not contradict semantic compositionality. The authors distinguish between 'idiomatic expressions' (e.g. kick the bucket) on the one hand and 'idiomatically combining expressions' on the other hand. Idiomatically combining expressions (ICEs) are semantically compositional and most LVCs fall into that class. After 
having identified the probable figurative meaning of the different components of an ICEs, its meaning can be build up compositionally. Such a compositional view is supported by the observation that ICEs come in families (e.g. Sag et al. 2002; see Gibbs and Nayak 1989; Nunberg et al. 1994; Fleischhauer and Neisani 2019 for further evidence supporting a compositional analysis of ICEs). Light Verb Constructions belonging to the same family instantiate the same interpretational pattern. For example, the LVCs in (2) which instantiate the pattern vor (lit. 'in front of') + NP + stehen 'stand' all have the same 'prospective' interpretation and can be paraphrased as 'be close to the change of state expressed by NP'.

(2) vor dem Ruin stehen 'to face ruin', vor dem Kollaps stehen 'to be at the brink of collapse', vor der Explosion stehen 'to be before the explosion/to be ready to explode', vor der Vollendung stehen 'to near completion', vor dem Abschluss stehen 'to near completion/to be before the end', vor dem Untergang stehen 'to be on the brink of decline', vor der Fertigstellung stehen 'to near completion'

The existence of families such as the one in (2) shows that the individual LVCs are not interpreted idiosyncratically but rather on the base of systematic interpretational patterns. In line with this, Nunberg et al. (1994) argue that the existence of such families would be surprising, if the members of the families were not built compositionally.

As a consequence of assuming compositionality, LVCs show a mismatch between syntactic and semantic composition: syntactically, the light verb is the head of the construction and realizes the nominal element as its complement whereas the nominal element is the semantic head contributing the major part of the meaning.

The semantic composition of light verb constructions has only rarely been adressed explicitly in the semantics literature. Noteable exceptions come from work on the composition of event structure (e.g. Karimi 1997; Folli et al. 2005; Pantcheva 2009) and from Butt and Geuder (2001). The work on event structure usually neglects lexical semantics and therefore only covers a part of the meaning of light verb constructions. The current paper aims at filling this gap by presenting a case study on the semantic composition of German LVCs of the 'prospective family' presented in (2).

\section{Case study: LVCs with stehen ('stand')}

German stehen 'stand' is basically a verb expressing the posture of its theme argument. In addition, it also allows for the specification of the theme's location by means of a spatial PP as in (3), The sentence in (3) has the interpretation that the subject referent Peter is in an upright posture and is located at a place denoted by vor dem Haus 'in front of the house'. The spatial preposition locates the referent of its external argument within a neighboring region of a reference object (cf. Wunderlich and Herweg 1991; Kaufmann 1995 among others). In the case of vor, the referent of the internal argument (Peter) is located in a spatial region in front of the reference object (the house). Following Talmy (1972) among others, we refer to the reference object as 'ground'.

Peter steht vor dem Haus. 'Peter is standing in front of the house.'

In (3), stehen 'stand' is used as a heavy verb. A light use of stehen is shown in (4), Its meaning is that the boiler is close to explosion but not that the boiler is spatially located in a preregion of the explosion event. Such a literal interpretation does not make sense since the event does not denote a location with respect to which an object can be located.

Der Kessel steht vor der Explosion. 'The boiler is close to explosion.'

The interpretation of (4) is that the boiler is in a state anterior to an explosion event. Such an interpretation is called 'prospective' in the aspectual literature (e.g. Comrie 1976, 64). This particular kind of light verb construction is one way of expressing prospective aspect in German although it is not a grammaticalized aspect construction. The prospective interpretation only arises with eventive nouns denoting a change of 
state such as Explosion 'explosion' or Vollendung 'completion'. Crucially, the meaning of the LVC in (4) is not that the boiler will definitely explode. Prospective aspect is weaker than the future tense and only expresses that if the boiler remains in its current state, this will possibly result in an explosion.

The LVC exploits the ability of the preposition to refer to both location in space and time relative to a spatial entity or an event. It is important to note that the preposition does not depend on the cooccurrence of a light verb (LV) such as stehen 'stand' to be able to express the fact that the event denoted by its internal argument is about to take place. This is clearly shown by the fact that a vor-PP can also be used attributively in this reading as illustrated by (5).

Ein Kessel kurz vor der Explosion ist eine große Gefahr.

'A boiler close to explosion is a great danger.'

As in the LVC in (4), the PP in (5) conveys the meaning that the event referred to by the PP-internal NP is close albeit not inevitable in spite of the absence of an LV. The LV therefore is not required for establishing this particular reading and can be regarded as more or less copula-like, selected in order to license a PP parallel to its heavy use. Another aspect central to the analysis of LVCs of the vor + NP + stehen-type is the selection of the subject argument in dependence of the argument structure of the PP-internal NP: Since the noun Explosion 'explosion' refers to an event with only a single participant undergoing the change of state referred to by the NP, it is exactly this argument which is selected as an argument to be realized as the subject of the LVC. However, if the PP-internal NP comes with a more complex argument structure as in (6), the LVC exhibits some flexibility in regard to subject choice:
a. Die Gemeinde steht kurz vor der Fertigstellung der Umgehungsstraße.
'The local community is about to complete the bypass.'
b. Die Umgehungsstraße steht kurz vor der Fertigstellung durch die Gemeinde.
'The bypass is about to be completed by the local community.'

In (6) the eventive noun Fertigstellung 'completion' derives from the transitive verb fertigstellen 'to complete' via ung-nominalization (see e.g. Ehrich and Rapp 2000 on ung-nominalization in German). As shown by the contrast between (6-a) and (b), either the actor or the theme argument of the underlying verb can be realized as subject of the LVC while the remaining argument is realized as a genitive NP as in (6-a) or via a durch-PP as in (b) depending on its semantic role (theme vs. actor).

Given the observations illustrated above, a proper analysis of LVCs of the type vor $+\mathrm{NP}+$ stehen has to account for at least (i) the way the meaning of the construction is derived compositionally given the meaning of the parts outside this construction and (ii) the selection of the subject argument on the base of the argument structure of the PP-internal NP.

\section{The framework: LTAG and frames}

\subsection{Frame semantics}

Frames emerged as a representation format of conceptual and lexical knowledge (Fillmore, 1982; Barsalou, 1992; Löbner, 2014). They are commonly presented as semantic graphs with labeled nodes and edges, as in Fig. 11, where nodes correspond to entities (individuals, events, ...) and edges to (functional or non-functional) relations between these entities. In Fig. 1 all relations except part-of are meant to be functional. This representation offers a fine-grained decomposition of meaning and should not be confused with the FrameNet frames, although the former can help to capture the structural relations of the latter (cf. Osswald and Van Valin, 2014).

Frames can be formalized as extended typed feature structures (Petersen, 2007; Kallmeyer and Osswald, 2013; Lichte and Petitjean, 2015), involving a finite set of types loc_state, house, person, ..., a finite set of attributes (partial functions from frame nodes to frame nodes) THEME, GROUND, LOCATION, .... and a finite set of (non-functional) relations, for instance part-of (which is a one to many mapping). Frame nodes are typed where we assume that a node can have more than one type (see the loc_state $\wedge$ 


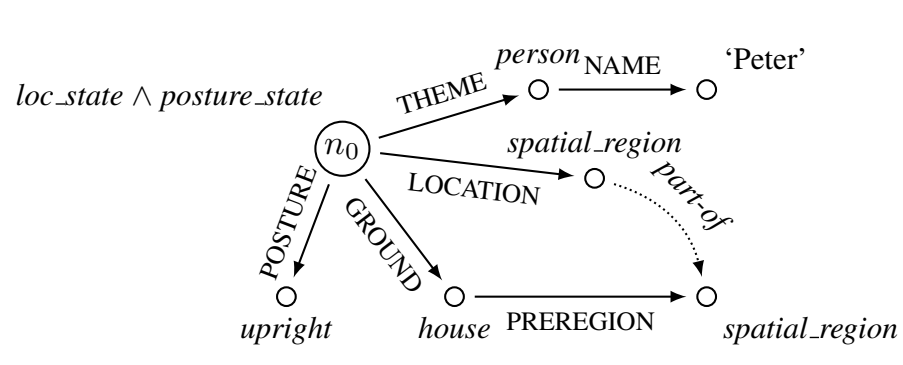

frame graph

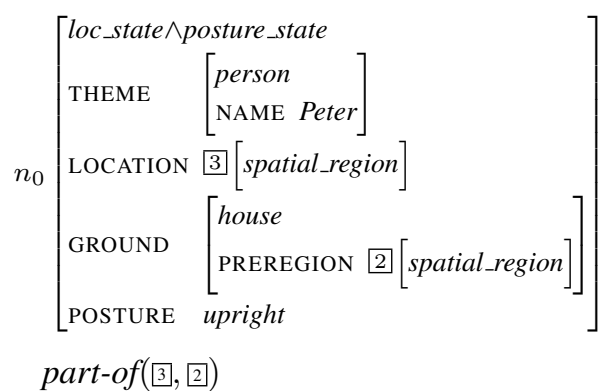

attribute-value matrix

Figure 1: Frame for (3) Peter steht vor dem Haus ('Peter is standing in front of the house')

posture state node in Fig. 1). We assume some of the frame nodes to be accessible via unique labels, in Fig. 1 for instance the label $n_{0}$ uniquely points to the loc_state $\wedge$ posture_state node of the frame. As mentioned above, frame nodes can be connected via functional attributes or via non-functional relations. We require however that every node in a frame is reachable from some labeled node via an attribute path, i.e., via a sequence of functional attributes ${ }^{1}$

Besides concrete frames, there is a frame signature that constrains the general form of semantic frames. Within this signature, we allow to define subtype relations (e.g., every loc_state is a state), type incompatibilities (e.g., nothing can be of type state and person at the same time), requirements for the existence of attributes for nodes of certain types (e.g., a state always has a THEME) etc. We will see more examples below.

\subsection{Lexicalized Tree Adjoining Grammars with frames}

For syntactic modeling and syntactic composition, we choose Lexicalized Tree Adjoining Grammar (LTAG Joshi and Schabes, 1997; Abeillé and Rambow, 2000). A LTAG consists of a finite set of elementary trees. Larger trees can be derived via the composition operations substitution (replacing a leaf with a new tree) and adjunction (replacing an internal node with a new tree). An adjoining tree has a unique non-terminal leaf that is its foot node (marked with an asterisk). When adjoining such a tree to some node $v$, in the resulting tree, the subtree with root $v$ from the old tree ends up below the foot node.

In order to capture syntactic generalizations, the non-terminal node labels are enriched with feature structures (Vijay-Shanker and Joshi, 1988). Each node has a top and a bottom feature structure (except substitution nodes, which have only a top). Nodes in the same elementary tree can share features. Substitutions and adjunctions trigger unifications: In a substitution step, the top of the root of the new tree unifies with the top of the substitution node. In an adjunction step, the top of the root of the adjoining tree unifies with the top of the adjunction site and the bottom of the foot of the adjoining tree unifies with the bottom of the adjunction site. Furthermore, in the final derived tree, top and bottom must unify in all nodes.

For the syntax-semantics interface, we pair LTAG elementary trees with semantic representations, in our case frames (Kallmeyer and Osswald, 2013). Syntactic nodes are enriched with (untyped) interface features such as I(NDIVIDUAL) and E(VENT) that contribute labels of nodes in the related semantic frame. Upon substitution and adjunction, the unification of interface features triggers the identification of frame node labels and, consequently, the unification of the linked semantic frames.

An example (involving only substitution) is given in Fig. 2. The three substitutions lead to $1=0$ (which unifies the frame contributed by Peter with the THEME of the loc_state), $0=4$ (which unifies the posture loc_state frame introduced by steht with the frame contributed by vor, thereby also unifying the GROUND of the former with the GROUND of the latter), $2=3$ (which unifies the LOCATION of the loc state with the first element of the part-of relation) and $5=8$ (which unifies the house frame with the value of the GROUND feature, whose PREREGION value is the second element of the part-of relation).

\footnotetext{
${ }^{1}$ This condition is important for restricting the computational complexity of unification, i.e, of merging two frames.
} 
As a result, we obtain the frame from Fig. 1 .

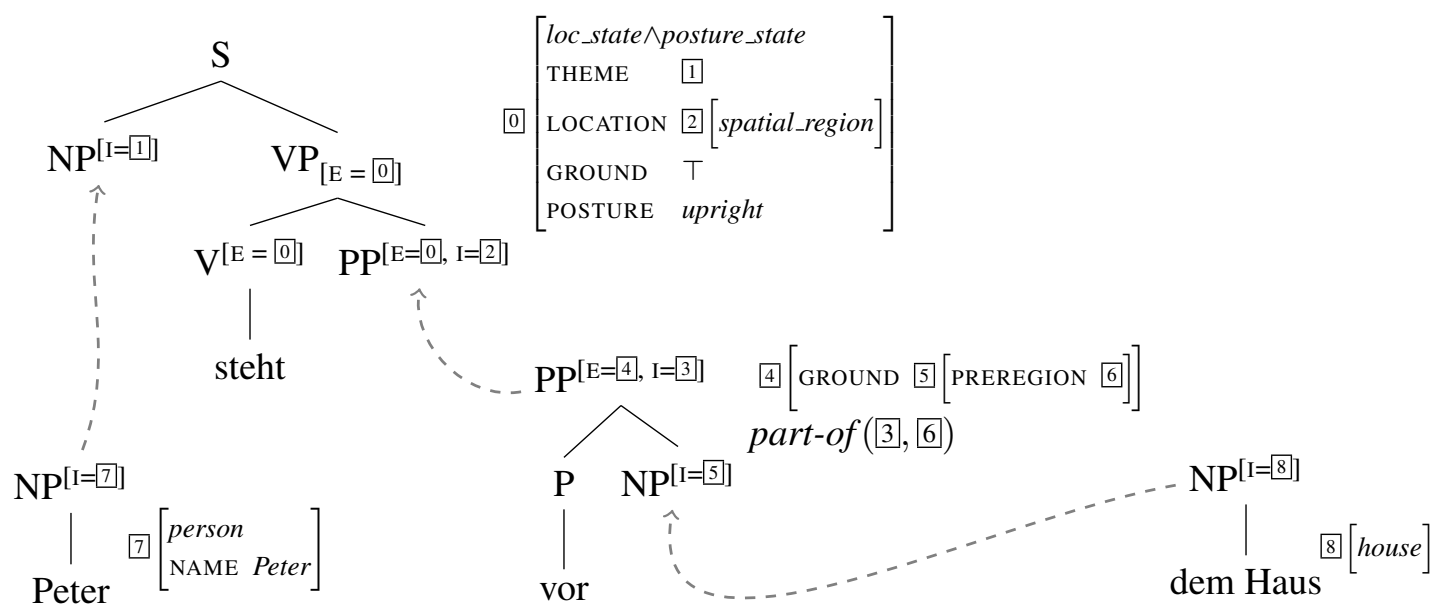

Figure 2: LTAG-frame derivation for (3), leading to the frame from Fig. 1

Generalizations over elementary tree frame pairs and constraints over frame types are captured in the so-called metagrammar in form of a principled and factorized description of syntactic and semantic building blocks. We will use this in the next sections when developing our analysis of LVCs with stehen.

There has been only very little work on computational implementations of LVCs so far that take both syntax and semantics into consideration. Vaidya et al. (2014) propose an LTAG analysis for certain LVCs in Hindi but, in contrast to our paper, do not deal with semantics. Their syntactic analysis is such that the light verb adjoins into the noun, i.e., the noun spans the entire subcategorization frame. This requires separate and largely unrelated analyses for the literal uses and the light verb uses of verbs such as stehen. Our analysis is more factorized and thereby more unified, and it establishes links between the subject NP and semantic arguments of the embedded event NP via appropriate frame unifications.

\section{The analysis}

In the following, we develop an analysis of LVCs of the type stehen + vor + NP, combined with an analysis of the literal use of stehen as in Fig. 11. The goal is to factorize into the contributions of literal and non-literal stehen, the contributions of the respective constructions (LVC with PP versus loc_state NP-V-PP), the contribution of the NP embedded in the PP within the LVC, and the contribution of the preposition vor. We will see, that the use of LTAG allows us to separate lexical contributions from constructional ones (the latter are paired with unanchored trees), and the use of frames, in particular of the type hierarchy, allows for elegant generalizations, specifically, for a uniform meaning of vor.

\subsection{Literal stehen versus LVC stehen + vor + NP}

As a first step towards decomposing (3) Peter steht vor dem Haus ('Peter is standing in front of the house') and (4) Der Kessel steht vor der Explosion ('The boiler is close to explosion') into form-meaning components, we assume that there are different constructions for the literal (3) and the LVC case (4). The former construction, nOVpploc is characterized as requiring a THEME NP and a LOCATION PP and it describes a loc state involving a theme, a location and a ground. It can, for instance, be anchored by stehen ('stand'), wohnen ('live'), liegen ('lie'), etc.). The latter, nOVpplvc, is more general, it describes a state (determined by the PP) and the subject NP contributes the THEME of that state. Fig. 3 shows the two constructions. The diamond marks the position of the lexical anchor.

Concerning the lexical anchor stehen, we assume that we have two different lexical entries, for the literal and the LVC reading respectively. In the literal case, the frame type is posture_state and we have 

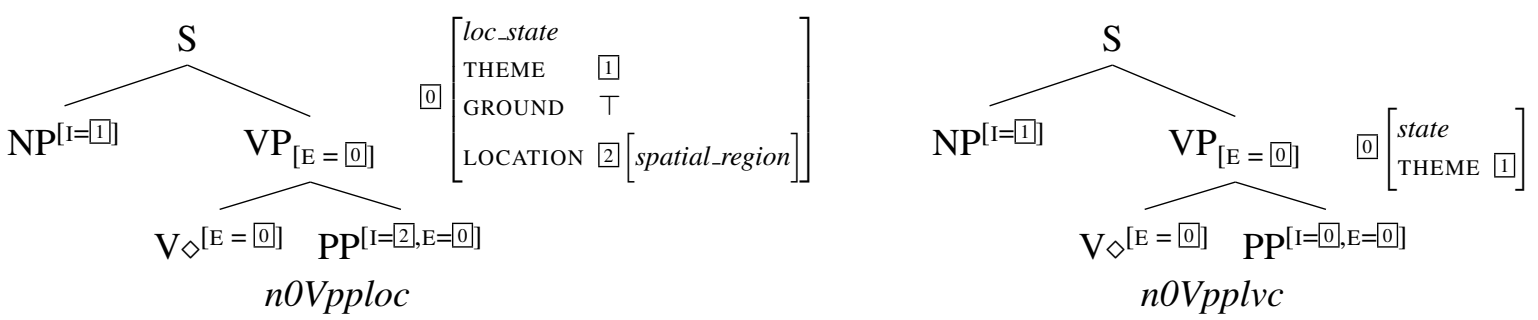

Figure 3: The two unanchored constructions

an attribute POSTURE = upright while in the LV case, the lexical entry only specifies the type as state $2^{2}$ The relation between the two readings is captured within our factorization of lexical entries. The literal reading extends the light verb reading by further restricting its type and adding the POSTURE attribute.

On an abstract level, the preposition vor expresses the same relation either between the LOCATION of the loc_state and the object denoted by the NP embedded in the PP or between the state itself and the event denoted by the PP-internal NP. In both cases, it means that the former is part of some PREREGION of the latter where PREREGION is to be understood in a very general way, not limited to spatial regions but including also prestates of events ${ }^{3}$ Along these lines, we define both spatial_region and state as incompatible subtypes of region, expressed in general frame constraints that are part of the type hierarchy:
a. spatial_region $\rightarrow$ region
b. state $\rightarrow$ region
c. $\quad$ state $\wedge$ spatial_region $\rightarrow \perp$

These constraints are taken to be universal quantifications over frame nodes, i.e., (7-a) is short for $\forall x[$ spatial_region $(x) \rightarrow$ region $(x)]$.

With these additional constraints, we can characterize the meaning contribution of vor as follows: vor establishes a relation part-of between the frame node contributed as I feature at the PP node (Peter's location or the state denoted by the light verb) and a GROUND (the house or the explosion) with respect to which the former is positioned. More precisely, it expresses that the location (resp. the state in the LVC case) is part of the PREREGION of the GROUND. Fig. 4

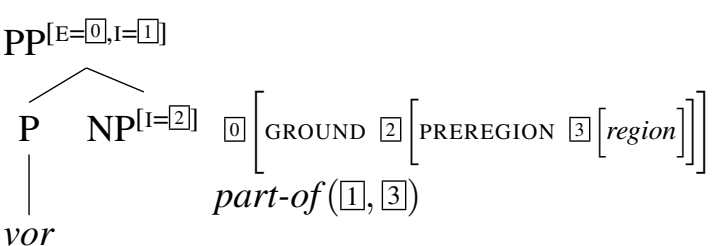

Figure 4: Anchored tree for the preposition vor. gives the corresponding elementary tree with its frame. When combining this with the loc_state construction, the interface feature I at the PP node provides the location, while in the LVC construction, it has the same value as the $\mathrm{E}$ feature, i.e., it provides the overall state. The relation part-of is defined between elements of type region with the additional constraint that the elements must have the same type (this excludes for instance a part-of relation between elements of the incompatible types spatial_region and state). We furthermore assume a general frame constraint stating that in a case where part-of relates two states, they must have identical THEME values.

The embedded NP provides an object coming with a certain topological structure in the literal meaning and an event in the LVC case. More concretely, house is of the more general type building, which comes with an INREGION, an ATREGION and also a PREREGION that can be addressed via corresponding prepositions. The values of these attributes are of type spatial_region. We assume constraints as in (8), (ATTR : type in some node $x$ is short for $\exists y[\operatorname{ATTR}(x, y) \wedge$ type $(y)]$.) With these constraints, the lexical entry of Haus can be restricted to giving the type house. The effect of the constraints will lead to the form meaning pair on the left of Fig.5.

\footnotetext{
${ }^{2}$ We might actually need a second literal reading without a POSTURE specification for sentences as Die Wolken stehen vor der Sonne ('The clouds are in front of the sun').

${ }^{3}$ We consider this abstract conception of PREREGION as allowing for (temporal) states as well as spatial regions as directly reflecting the metaphorical relation between the literal spatial reading of the preposition and the figurative temporal interpretation. Consequently, our analysis takes up ideas of conceptual metaphors such as "time is space" (Lakoff and Johnson, 1980) while it also offers a concrete formal treatment of such figurative processes.
} 


$$
\begin{array}{ll}
\text { a. } & \text { house } \rightarrow \text { building } \\
\text { b. } & \text { building } \rightarrow \text { INREGION : spatial_region } \\
\text { c. } & \text { building } \rightarrow \text { ATREGION : spatial_region } \\
\text { d. } & \text { building } \rightarrow \text { PREREGION : spatial_region }
\end{array}
$$
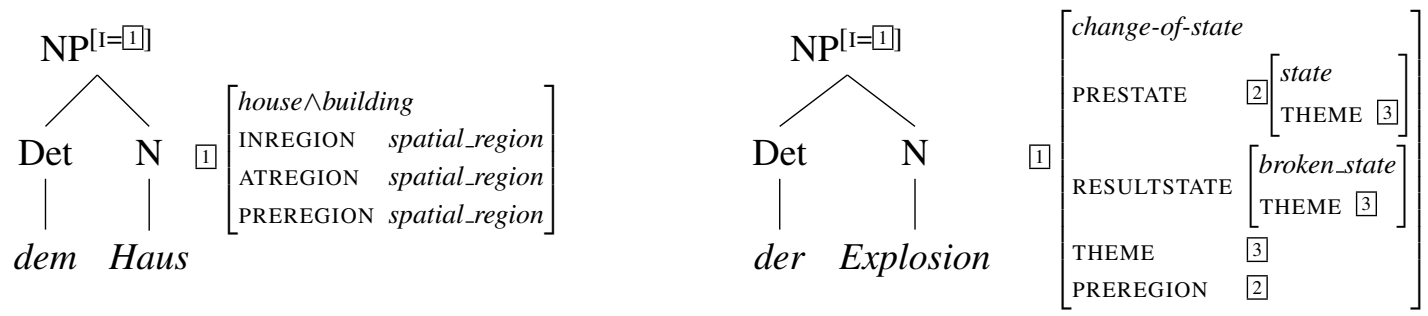

Figure 5: Anchored elementary trees for the NPs embedded in the PP in (3) and (4)

Explosion, in contrast, denotes an event of type change-of-state with a RESULTSTATE of type broken_state. Furthermore, we assume the general constraints in (9) and (10) stating that a change-of-state has a PRESTATE, and a RESULTSTATE, all of them having as THEME the THEME of the overall change of state. ( $\triangleq$ stands for path equality, i.e., structure sharing: ATTR $1 \triangleq$ ATTR 2 in some node $x$ corresponds to $\exists y[\operatorname{ATTR} 1(x, y) \wedge \operatorname{ATTR} 2(x, y)]$.) Note that although we assume that a change of state always comes with a PRESTATE, this PRESTATE is not part of the event structure encoded by an eventive noun such as Explosion. This is evident if one looks at the referents of event nouns which are subject to polysemy but never include a PREREGION as a potential referent (see Kawaletz and Plag 2015 for a frame account of the polysemy of event nominalizations). Likewise, although a spatial object has some (possibly variable) PREREGION, this region is not a part of it. Therefore, PRESTATE has to be differentiated from some event internal INITIAL STATE which precedes the RESULT STATE and in which the result does not hold yet. Since the phenomena we account for do not require reference to the INITIAL STATE of a change-of-state frame, INITIAL STATE is not represented in the change-of-state frame for the sake of simplicity. Furthermore, the PRESTATE is also the PREREGION of the event. Combining these constraints with the lexical entry for Explosion yields the elementary tree frame pair on the right of Fig. 5 .

$$
\begin{aligned}
& \text { a. } \quad \text { change-of-state } \rightarrow \text { PRESTATE }: \text { state } \\
& \text { b. } \quad \text { change-of-state } \rightarrow \text { RESULTSTATE }: \text { state } \\
& \text { a. } \quad \text { change-of-state } \rightarrow \text { THEME } \triangleq \text { PRESTATE }: \text { THEME } \\
& \text { b. } \quad \text { change-of-state } \rightarrow \text { THEME } \triangleq \text { RESULTSTATE }: \text { THEME } \\
& \text { c. change-of-state } \rightarrow \text { PREREGION } \triangleq \text { PRESTATE }
\end{aligned}
$$

For the literal case (3), we have already seen in Fig. 2 how the form meaning fragments are put together. Fig. 6 shows the LTAG derivation for (4), The syntactic composition triggers unifications between 1 and 7, between 0,3 and 4 , and between 5 and 8 . Furthermore, the constraints on part-of relations lead to a unification of 1 and 11, the THEME attributes of the two states that are related.

The resulting frame is given in Fig. 7. According to this frame, the boiler is in a state that is part of the prestate of its explosion 4

A combination of a vor-PP embedding a change-of-state NP with the literal loc_state construction is excluded because it would lead to a part-of relation between a spatial_region and a state, two types that

\footnotetext{
${ }^{4}$ Note that the temporal structure of the explosion event in relation to its prestate is only implicit in this frame. The prestate stands in a precedes relation to the change of state, which in turn stands in an overlap relation to the result state. In other words, the state represented in Fig 7 is such that the explosion has not happened yet. Furthermore, we assume that the fact that a prestate holds does not necessarily entail the event itself, i.e., is compatible with a situation where the event never happens. Note, however, that this is only implicit since the frame semantics used here does not distinguish between instantiated frames and frames that are rather frame types. In future work, we will explore ways to explicitly include uninstantiated frames (in other words complex frame types) along the lines of Balogh and Osswald (2017), which is close to what we find in Type Theory with Records (TTR, Cooper 2012).
} 


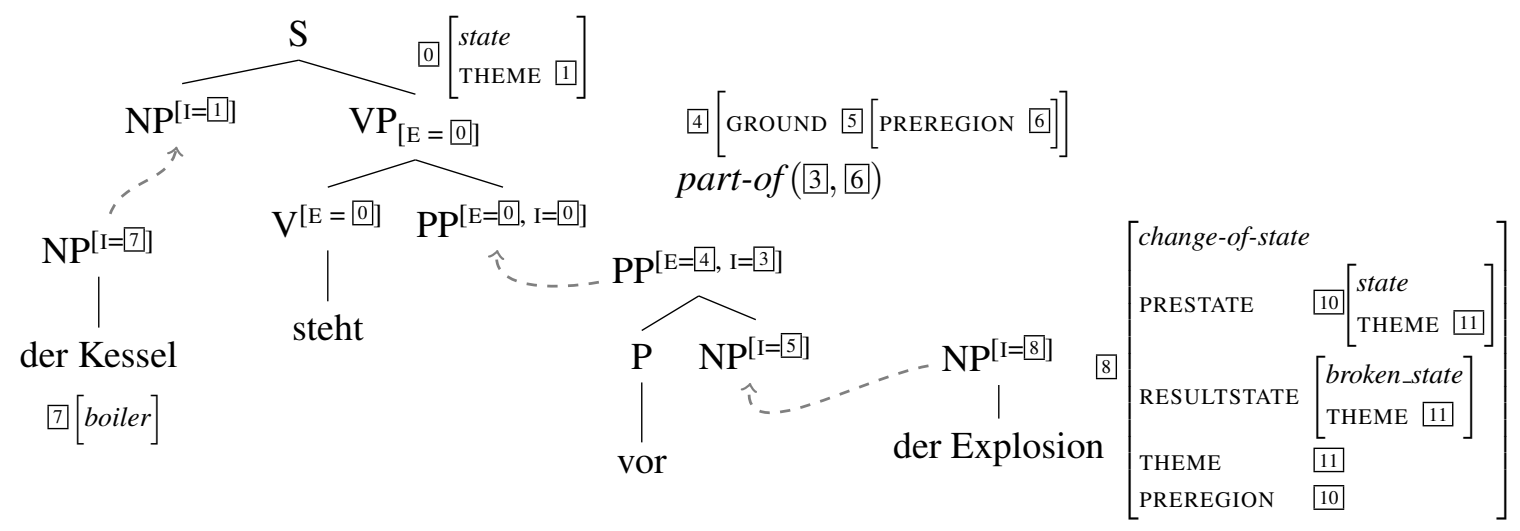

Figure 6: LTAG-frame derivation for (4)
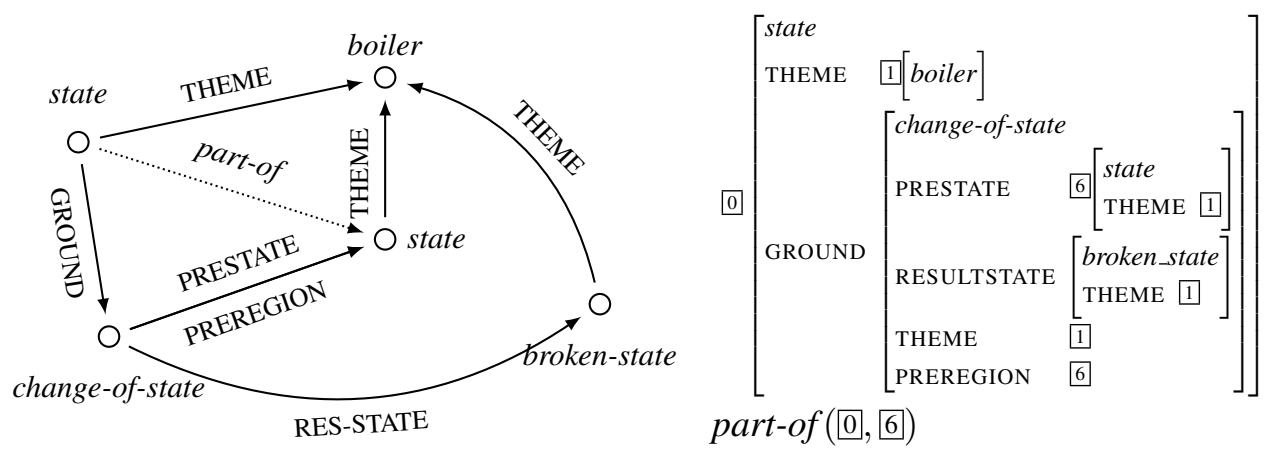

Figure 7: Frame for (4)

are not unifiable $\sqrt{5}^{5}$ For the same reason, the combination of the LVC construction with a PP embedding a building NP is ruled out.

\subsection{LVCs with an NP event that has actor and undergoer}

Now let us turn to LVCs involving stehen and a vor-PP with a noun that denotes an accomplishment involving an actor and a theme. An example was Fertigstellung ('completion') in (6), repeated below:
a. Die Gemeinde steht kurz vor der Fertigstellung der Umgehungsstraße.
'The local community is about to complete the bypass.'
b. Die Umgehungsstraße steht kurz vor der Fertigstellung durch die Gemeinde.
'The bypass is about to be completed by the local community.'

The additional complication, compared to vor der Explosion stehen is that both the actor or the theme of the event denoted by the noun embedded in the PP can be realized as the subject NP of the LVC. Depending which argument is realized as the subject, the interpretation varies slightly. The LVC makes a predication about the local community in (11-a) whereas it predicates about the bypass in (11-b), This results in a more active-like reading for (11-a) as the actor is the subject of the complex predicate, and in a more passive-like reading for (11-b) However, the prestate remains unspecified apart from being a prestate of a particular event and as such being affected by it. We leave it for future research to explore potential semantic asymmetries between realization variants of the type illustrated in (11).

\footnotetext{
${ }^{5} \mathrm{~A}$ reviewer remarks that this restriction is too strong. However, apparent counterexamples involving the literal meaning of stehen with a PP-internal noun referring to a change of state involve some kind of coercion such that the event is shifted to the place where it takes place. For instance, in a sentence such as Die Ingenieure standen direkt vor der Explosion 'The engineers were standing right in front of the explosion' vor der Explosion is interpreted as 'in front of the place where the explosion happened'.
} 
We pursue a similar analysis as in the case of a changeof-state, namely that the LVC stehen vor NP indicates that the subject is in a prestate of the NP event. The notion of prestate is, however, less fixed in the case of Fertigstellung since both actor and theme can be the theme of the prestate, depending on the structure of the NP. Roughly, if the NP event has an active-like interpretation $(\mathrm{N}+$ genitive $\mathrm{NP}$ denoting the theme), the prestate refers to the actor as

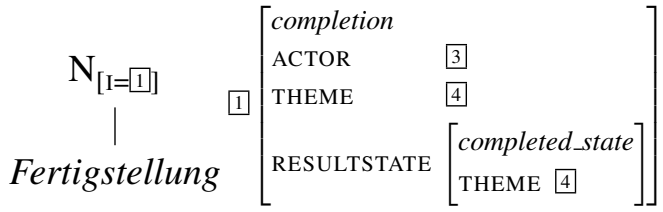

Figure 8: Lexical meaning of Fertigstellung ('completion') in (11-a) and if it has a passive-like reading ( $\mathrm{N}+$ durch-PP denoting the actor), the prestate refers to the theme as in (11-b). In other words, there are different constructions that come with different specifications of the THEME of the PRESTATE. The (simplified) lexical meaning contribution of Fertigstellung is given in Fig. $8^{6}$

This can then anchor either of the two constructions (unanchored trees) in Fig. 9. $N n_{\text {gen }}$ represents
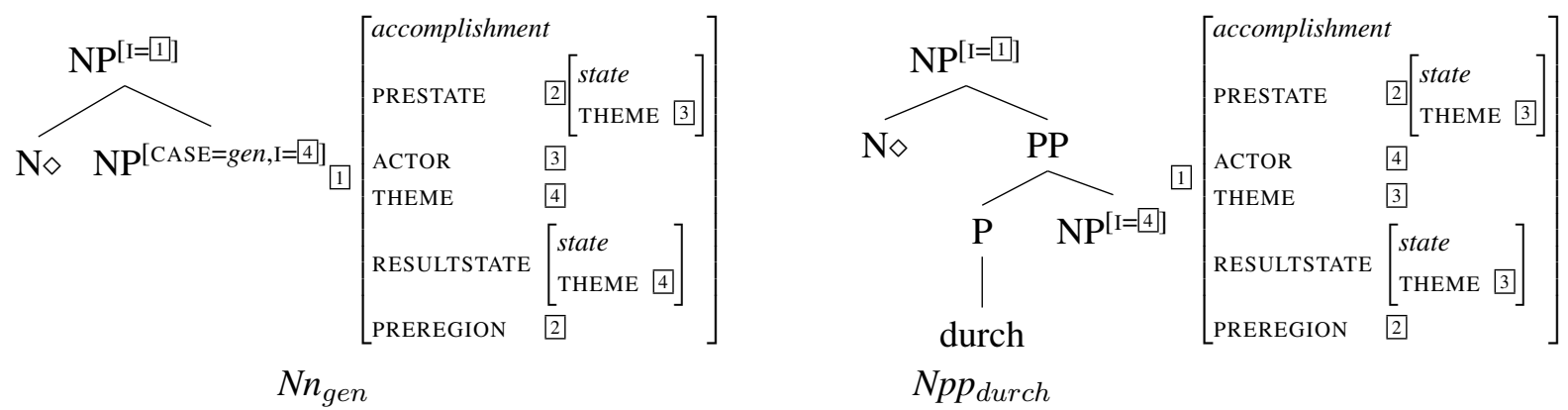

Figure 9: Unanchored elementary trees for accomplishment denoting nouns

an NP with a genitive argument slot that contributes the theme while the actor is not realized. In this case, the theme of the prestate is the actor. In the second construction, $N p p_{d u r c h}$, a PP with preposition durch realizes the actor inside the NP while the theme is missing. In this case, the prestate of the event concerns the theme. Combining the respective anchored trees with the trees for the LVC construction yields the two desired readings.

Semantically ill-formed sentences such as (12) can then be excluded by type constraints for semantic roles. An actor has to be capable of volition, which is not the case for objects such as bypass. Therefore, the bypass cannot be the actor of completion.

$$
\begin{aligned}
& \text { \#die Umgehungsstraße steht vor der Fertigstellung der Planung } \\
& \text { 'the bypass is close to finishing the planning' }
\end{aligned}
$$

\subsection{Implementation}

In order to check the theoretical analyses presented in the previous sections, we created a toy grammar consisting of the pairs of LTAG trees and frames appearing in our examples:7 The grammar was developed using XMG-2 (Petitjean et al., 2016), a grammar engineering tool based on the notion of metagrammar. In this framework, developing a grammar consists in writing a compact and factorized description, called the metagrammar. This linguistic resource, consisting of reusable abstractions described using logic and constraints, is compiled with XMG-2 to obtain the non-factorized grammar. Such a grammar can be used for parsing, thereby allowing to check that automatic semantic analyses are consistent with the ones that we presented. To do so, we used the parser TuLiPA for LTAG and semantic frames (Arps

\footnotetext{
${ }^{6} \mathrm{We}$ ignore here the fact that Fertigstellung is derived from the verb fertigstellen via -ung nominalization and that this also should be modeled in a principled way within the syntax-semantics interface. For possible analyses of such phenomena using frames see for instance Andreou and Petitjean (2017).

'Our implementation and the instructions to experiment with it are available online:

https://github.com/spetitjean/XMG-2/tree/master/MetaGrammars/synframe/LVC
} 
and Petitjean, 2018), giving as parameters the toy grammar and its type hierarchy. TuLiPA was able to compute the expected derivations for all the examples.

\section{Conclusion and future work}

In this paper, we develop a compositional analysis of the semantics of German LVCs involving the posture verb stehen ('stand') and a vor-PP. The chosen framework combines LTAG with frames, which comes with constructionist elements (LTAG) and with the possibility to formulate general semantic constraints via frame types and constraints on the type hierarchy. This allows us to propose an analysis that has the following features: It separates the meaning contribution of the light verb from the form-meaning contribution of the different constructions (literal location-state versus LVC-vor-PP construction). Furthermore, it assumes a single uniform tree-frame pair for the preposition vor, which establishes a part-of relation between a region (the location in the literal case and the state in the LVC case) and the preregion of the frame of the PP-internal NP (the spatial region in front of an object in the literal case and the prestate of an event in the LVC case). Unifications triggered by syntactic composition lead to a further specification of the type of region/preregion and part-of relation. Moreover, our analysis also distinguishes different constructions for eventive nouns, depending on the NP-internal syntactic realization of their arguments. This allows for a construction-specific specification of the participant of a prestate of the event, which leads to the possibility to identify the theme of the state denoted by the light verb either with the actor or the theme of the PP-internal event, depending on the structure of the NP.

Even though this paper covers only a few cases of LVCs, it shows clearly that the combination of a constructionist syntactic approach with frame semantics yields elegant means of generalization and allows for a large degree of decomposition and factorization concerning the various form-meaning pairs.

As a next step, the analysis presented within the current paper should be extended to cover further families of stehen-LVCs. There exist further families using the same preposition (13), as well as LVCs using different prepositions (e.g. außer 'without' or $z u$ 'to'). The LVCs in (13) at first sight seem to be instances of the pattern discussed above. However, they do not have a prospective interpretation, rather they express that the subject is confronted with a certain task or question. Two particularly interesting questions are: first, what is the semantic contribution of the LV and second, how is the preposition interpreted. Especially with respect to the P element, it is clear that it cannot have the same interpretation as in the prospective-family discussed in this paper.

vor einer Frage stehen 'to be faced with a question', vor einer Aufgabe stehen 'to be confronted with a task', vor dem Problem stehen 'to be confronted with a problem'

The compositional analysis presented within the current paper is somewhat incomplete, as we ignored the semantic contribution of the article. Contrary to e.g. Leiss (2000), it seems reasonable to claim that the article has a semantic function since its use is not fixed (14). To yield a compositional analysis of the entirely LVC, the contribution of the article needs to be integrated as well.

a. Die Fabrik steht vor der Explosion. 'The factory is close to explosion.'

b. Die Fabrik steht vor einer erneuten Explosion. 'The factory is close to explosion again.'

The current paper presents a promising first step in the compositional analysis of LVCs, which will be extended along the lines sketched above.

\section{Acknowledegments}

We would like to thank three anonymous reviewers for their valuable comments that contributed to improving the paper. The work presented in this article was partially funded by the German Science Foundation (DFG) as part of CRC 991 and by the European Research Council (ERC grant TreeGraSP). 


\section{References}

Abeillé, A. and O. Rambow (2000). Tree Adjoining Grammar: An Overview. In A. Abeillé and O. Rambow (Eds.), Tree Adjoining Grammars: Formalisms, Linguistic Analyses and Processing, pp. 1-68. Stanford, CA: CSLI Publications.

Andreou, M. and S. Petitjean (2017). Describing derivational polysemy with XMG. In I. Eshkol and J.-Y. Antoine (Eds.), Actes de TALN 2017, 24 e Conférence sur le Traitement Automatique des Langues Naturelles, Volume 2, pp. 94-101.

Arps, D. and S. Petitjean (2018). A parser for LTAG and frame semantics. In Proceedings of LREC 2018, pp. 2223-2229.

Balogh, K. and R. Osswald (2017). A frame-based analysis of verbal particles in Hungarian. Manuscript.

Barsalou, L. W. (1992). Frames, concepts, and conceptual fields. In A. Lehrer and E. F. Kittay (Eds.), Frames, Fields, and Contrasts, New Essays in Semantic and Lexical Organization, Chapter 1, pp. 21-74. Hillsdale, New Jersey: Lawrence Erlbaum Associates.

Butt, M. and W. Geuder (2001). On the (Semi)Lexical Status of Light Verbs. In N. Corver and H. van Riemsdijk (Eds.), Semilexical Categories: On the content of function words and the function of content words, pp. 323-370. Berlin: Mouton.

Comrie, B. (1976). Aspect. Cambridge: Cambridge University Press.

Cooper, R. (2012). Type theory and semantics in flux. In R. Kempson, N. Asher, and T. Fernando (Eds.), Philosophy of Linguistics Handbook of the Philosophy of Science, pp. 271-323. Elsevier BV.

Ehrich, V. and I. Rapp (2000). Sortale Bedeutung und Argumentstruktur: ung-Nominalisierungen im deutschen. Zeitschrift für Sprachwissenschaft 19.2, 245-303.

Fellbaum, C., A. Geyken, A. Herold, F. Koerner, and G. Neumann (2006). Corpus-based studies of German idioms and light verbs. International Journal of Lexicography 19 (4), 349-360.

Fillmore, C. J. (1982). Frame semantics. In Linguistics in the Morning Calm, pp. 111-137. Seoul: Hanshin Publishing Co.

Fleischer, W. (1997). Phraseologie der deutschen Gegenwartssprache (2. Edition ed.). Tübingen: Niemeyer.

Fleischhauer, J. and M. Neisani (2019). Adverbial and attributive modification of persian separable light verb constructions. Journal of Linguistics, 1-41.

Folli, R., H. Harley, and S. Karimi (2005). Determinants of event type in Persian complex predicates. Lingua 115, 1365-1401.

Gibbs, R. W. and N. P. Nayak (1989). Psycholinguistic studies on the syntactic behavior of idioms. Cognitive Psychology 21, 100-138.

Joshi, A. K. and Y. Schabes (1997). Tree-adjoining grammars. In G. Rozenberg and A. Salomaa (Eds.), Handbook of Formal Languages. Vol. 3: Beyond Words, pp. 69-123. Berlin: Springer.

Kallmeyer, L. and R. Osswald (2013). Syntax-driven semantic frame composition in Lexicalized Tree Adjoining Grammar. Journal of Language Modelling 1, 267-330.

Karimi, S. (1997). Persian complex verbs: Idiomatic or compositional. Lexicology 3(2), 273-318.

Kaufmann, I. (1995). Konzeptuelle Grundlagen semantischer Dekompositionsstrukturen: Die Kombinatorik lokaler Verben und prädikativer Komplemente. Tübingen: Niemeyer. 
Kawaletz, L. and I. Plag (2015). Predicting the semantics of english nominalizations: A frame-based analysis of -ment suffixation. In P. S. . L. K. L. Bauer (Ed.), Semantics of Complex Words, pp. 289319. Dordrecht: Springer.

Lakoff, G. and M. Johnson (1980). Metaphors we live by. Chicago: University of Chicago Press.

Leiss, E. (2000). Artikel und Aspekt. Berlin/New York: Walter de Gruyter.

Lichte, T. and S. Petitjean (2015). Implementing semantic frames as typed feature structures with XMG. Journal of Language Modelling 3(1), 185-228.

Löbner, S. (2014). Evidence for frames from human language. In T. Gamerschlag, D. Gerland, R. Osswald, and W. Petersen (Eds.), Frames and Concept Types. Applications in Language and Philosophy, Volume 94 of Studies in Linguistics and Philosophy, pp. 23-67. Dordrecht: Springer.

Nunberg, G., I. A. Sag, and T. Wasow (1994). Idioms. Language 70(3), 491-538.

Osswald, R. and R. D. Van Valin (2014). FrameNet, frame structure, and the syntax-semantics interface. In T. Gamerschlag, D. Gerland, R. Osswald, and W. Petersen (Eds.), Frames and Concept Types. Applications in Language and Philosophy, Volume 94 of Studies in Linguistics and Philosophy, pp. 125-156. Dordrecht: Springer.

Pantcheva, M. (2009). First Phase Syntax of Persian Complex Predicates: Argument Structure and Telicity. JSAL 2(1), 53-72.

Petersen, W. (2007). Representation of concepts as frames. The Baltic International Yearbook of Cognition, Logic and Communication 2, 151-170.

Petitjean, S., D. Duchier, and Y. Parmentier (2016). XMG2: Describing description languages. In M. Amblard, P. de Groote, S. Pogodalla, and C. Retoré (Eds.), Proceedings of Logical Aspects of Computational Linguistics (LACL) 2016, Nancy, December 2016, Number 10054 in Lecture Notes in Computer Science, Berlin, pp. 255-272. Springer.

Sag, I., T. Baldwin, F. Bond, A. Copestake, and D. Flickinger (2002). Multiword Expressions: A Pain in the Neck for NLP. In A. Gelbukh (Ed.), Computational linguistics and intelligent text processing, pp. 1-15. Berlin: Springer.

Talmy, L. (1972). Semantic Structures in English and Atsugewi. Ph. D. thesis, University of California, Berkeley.

Vaidya, A., O. Rambow, and A. Palmer (2014). Light verb constructions with 'do' and 'be' in Hindi: A TAG analysis. In Proceedings of the Workshop on Lexical and Grammatical Resources for Language Processing, Coling 2014, pp. 127-136.

Vijay-Shanker, K. and A. K. Joshi (1988). Feature structures based tree adjoining grammar. In Proceedings of COLING, Budapest, pp. 714-719.

Wunderlich, D. and M. Herweg (1991). Lokale \& Direktionale. In A. von Stechow and D. Wunderlich (Eds.), Semantik - Ein internationales Handbuch zeitgenössischer Forschung, pp. 758-785. Berlin/New York: de Gruyter. 